\title{
CLIMATE CHANGE RESEARCH - WHAT DO WE NEED REALLY?
}

\author{
P. RAMA CHANDRA PRASAD \\ Lab for Spatial Informatics, International Institute of Information Technology \\ Gachibowli, Hyderabad - 500032, Telangana, India \\ rcprasad@iiit.ac.in,rcp_ncmsl@yahoo.co.in
}

\begin{abstract}
This research note focuses on the current climate change research scenario and discusses primarily what is required in the present global climate change conditions. Most of the climate change research and models predict adverse future conditions that have to be faced by humanity, with less emphasis on mitigation measures. Moreover, research ends as reports on the shelves of scientists and researchers and as publications in journals. At this juncture the major focus should be on research that helps in reducing the impact rather than on analysing future scenarios of climate change using different models. The article raises several questions and suggestions regards climate change research and lays emphasis on what we really need from climate change researchers.
\end{abstract}

KEY WORDS: Climate change, species extinction, models, house sparrow, bees.

\section{INTRODUCTION}

In the current scenario, we find a major focus on climate-change research linking up with biodiversity, species richness, ecosystem productivity and so on (Thompson et al. 2009, Nancy et al. 2013). In fact, nature is the prime for the survival of biota and any change in it will definitely collapse or disrupt the ecological equilibrium (this could be a layman's universal truth). This we all know, since for several decades, researchers and scientists and "nature conservationists" have been working on different aspects 
of nature, with a view to identifying the impact on it of a changing climate. But if we look globally, a minority or even a majority of the research is restricted to the running of projects, teaching in capacity-building programmes, publishing papers and raising the level of our personal credentials- "are we really concerned about things in relation to what we are doing in the so-called research? Moreover, research starts with a negative hypothesis, such as what happens if a given parameter is increased, or if population impact is increased (it is some pre-determined research).

\section{CURRENT RESEARCH}

The researchers/authors, who publish their research work, finally give some kind of mitigation, protection or conservation measures in their papers. But how far do they think their suggestions are taken, or indeed does any organization utilise their suggestions and come up with positive results? Are these scientists bothered either? The research outputs (suggestions/mitigation solutions) if not implemented (or rather not in a condition to be implemented) or practised beg a question as to what the use of such scientific research really is? Just to create panic in the community about the future or to generate reports and papers ending up in the cupboards of the authors.

Indeed, if we observe carefully, we find that all the studies end up with negative results, perhaps for the current period or for predicting scenarios. What we know for sure is that there are changes, and changes have an adverse impact on each and every thing that dwells on the Earth. So what is the solution and how to implement it or find ways to implement? (What are the efforts made by the researchers?).

Of course, there are negative changes, which we have to agree on, and these are $100 \%$ anthropogenic, and this fact we have been hearing about for decades. The so-called "models" are predicting some kinds of scenario and they are biased themselves, hence the existence of different scenarios offering predictions for the same regions (Liu et al. 2014, Chen et al. 2015). It is fine that models give a kind of warning and hint about future threats. Agreed, but working on the same concepts for a long time (decades and decades) will not give any kind of solutions. Rather, the work provides a kind of replication of similar studies using different data and models with varied projections and predictions.

\section{WHAT DO WE NEED REALLY?}

Currently what is expected is a kind of solution that combats the above kind of negative effect. There is much need to focus on some kind of positive studies showing how we can reduce impacts. If studies of such kinds are already done, it is better to share such things that may be helpful for other regions to replicate or apply in their regions. Why do researchers (we) not focus on studies on something like what will happen if we 
increase greenery? If we take some measures, to reduce pollution or how conservation of water bodies improve climate conditions? How can we control or at least limit or minimise climate changes? How will a positive approach enhance climate? And so on.

When we talk about climate change, we put together so many facts, figures, analyses and scenarios. These may be realistic and are probably looking on as global issues. But we have to realise that the concept of cellular organisation (cell to organism) applies. Similarly a local- (indeed personal-) level disturbance is gradually exaggerated as regional and continental threats.

So now we think of ourselves just as ordinary people (maybe laypeople), with no scientific background, and examine/question ourselves: what is my contribution to the so far threatened "climate changes"? How in daily life do I myself contribute to the disaster, and what are the measures I am taking to mitigate it? A local- or personal-level realisation is more of concern than scientific models and predictions which go their own way, without providing any suitable solutions.

\section{CONSERVATION}

With reference to climate change and biodiversity we often use the word "Conservation Biology". This term is used more or less loosely, without actually saying how we are really into conservation. Sitting in air-conditioned rooms or at a round-table conference, we just end up with "talk", without providing significant contributions to the subject being discussed. We have to remember that "when I preach something to somebody, I first have to follow".

When we ask somebody why we need to have a conservation concept, the answer will be global warming, climate changes, etc., the threat to biodiversity; so there is an urgent need for conservation. But what are the reasons for these changes? Obviously "we ourselves". We always say human beings are causing a threat of climate change, but who are those "human beings" really? Who is damaging the ecosystem? And are we not part of that group? Are those so-called "human beings" in fact "aliens"?

Conservation, restoration, resilience are some of the "hot words" generally used in scientific contexts. A great deal of debate and discussion takes place in the scientific community on the conservation of species, communities, the landscape, the large scale, the micro-scale, etc. But one thing we have to realise is why we are trying to talk about something which we really are not doing and may not be able to do. Apart from not realising simple things about how we are causing a threat to some of the organisms (species) which are around us.

Are we really concerned about and aware of, the reasons for the declines in the populations of house sparrows, bees, bats and some insects which we encounter daily in our areas? These organisms are more threatened by radiation from the mobile phones which we use continuously. There are case studies to show a decrease in sparrow populations and in some localities, especially urban areas, the house sparrow is almost 
extinct (Gulati 2005, Dandapat et al. 2010). The bees which we are fond of as pollinators are not able to trace their routes back to their hives because of interrupted radiation emitted by our cell phones (Korall et al. 1988, Harst et al. 2006, Sharma 2008, Kumar 2011, Sahib 2011). Bats in urban areas are at risk of dying when the temperature in a city approaches $40^{\circ} \mathrm{C}$ (Parris and Hazell 2005, Welbergen et al. 2008, Welbergen 2012).

If we are really interested in conservation, we have to look into such kinds of local conditions and come up with some solutions about how to overcome such problems, bring awareness in the community, campaign, and create fora. We are forgetting the threat we are causing to our local species and worried about some populations like gorillas, chimpanzees, wolves, etc., which are far away from us and not directly affected by us.

\section{CONCLUSIONS}

Now this is the phase in which we have to end the era of exaggerating the impact of climate change. As long as the human population is increasing these changes show an exponential trend. Our motto should be revised in a more generic way of identifying different ways to curtail the worst scenarios that may spring up in the future. More knowledge should be shared or case studies or research is required on the positive side relating to the improvement of conditions. So far what we are doing is "sitting on the branch of a tree and cutting the same one, then preaching for conservation and protection".

The modern technology and knowledge along with young manpower should come up with different new avenues of providing solutions to mitigate the coming disaster. The research should also be along the same lines and should not be done for the sake of projects or publications. The capacity-building programmes/research dissemination should be based on some positive case studies to show how one can improve climatic changes or at least limit them. The simple case studies that can make change - involve identifying vacant land and going for plantations, conserving and restoring bodies of water in one's local area, to make a little change in the current scenarios. If we discuss we can have more. Please try to have a positive research approach, if you are real conservers of nature!

\section{REFERENCES}

Chen J., Brissette F. P., Lucas-Picher P., 2015, Assessing the limits of bias-correcting climate model outputs for climate change impact studies, J. Geophys. Res. Atmos., 120, 1123-1136. Dandapat A., Dipak Banerjee, Dibyendu Chakraborty, 2010, The case of the Disappearing House Sparrow (Passer domesticus indicus), Veterinary World, 3, 2, 97-100.

Gulati V., 2005, House Sparrow on Verge of Extinction, Tribune News Service, Chandigarh, India. 
Harst W., Kuhn J., Stever H., 2006, Can electromagnetic exposure cause a change in behaviour? Studying possible non-thermal influence on honey bees - an approach within the framework of education informatics, Acta Systemica, 6, 1-6.

Korall H., Leucht T., Martin H., 1988, Bursts of magnetic fields induce jumps of misdirection in bees by a mechanism of magnetic resonance, Journal of Comparative Physiology, A, 162, 279-84.

Kumar N. R., Sangwan S., Badotra P., 2011, Exposure to cell phone radiations produces biochemical changes in worker honey bees, Toxicology International, 18, 1, 70-72.

Liu M., Rajagopalan K., Chung S. H., Jiang X., Harrison J., Nergui T., Guenther A., Miller C., Reyes J., Tague C., Choate J., Salathé E. P., Stöckle C. O., Adam J. C., 2014, What is the importance of climate model bias when projecting the impacts of climate change on land surface processes?, Biogeosciences, 11, 2601-2622.

Nancy B. G., Chapin III F S., Bierwagen B., Gonzalez P., Groffman P.M., Luo Y., Melton F., Nadelhoffer K., Pairis A., Raymond P. A., Schimel J., Williamson C. E., 2013, The impacts of climate change on ecosystem structure and function, Frontiers in Ecology and the Environment, 11, 474-482.

Parris K. M., Hazell D. L., 2005, Biotic effects of climate change in urban environments: The case of the grey-headed flying-fox (Pteropus poliocephalus) in Melbourne, Australia, Biological Conservation, 124, 2, 267-276.

Sahib S. S., 2011, Electromagnetic Radiation (EMR) Clashes with Honey Bees International, Journal of Environmental Sciences, 1, 5, 897-900.

Sharma A., 2008, Biochemical changes in Apis mellifera L. Worker Brood Induced by Cell Phone Radiation, M Phil. Thesis, Department of Zoology, Chnadigarh India, Punjab University, Chnadigarh.

Thompson I., Mackey B., McNulty S., Mosseler, A., 2009, Forest Resilience, Biodiversity, and Climate Change, A synthesis of the biodiversity/resilience/stability relationship in forest ecosystems, Secretariat of the Convention on Biological Diversity, Montreal, Technical Series, 43, $67 \mathrm{pp}$.

Welbergen J. A., 2012, Impacts of extreme events on biodiversity - lessons from die-offs in flying-foxes, Proceedings of the International Symposium on the importance of Bats as Bioindicators, Granollers, Barcelona.

Welbergen J. A, Klose S. M., Markus N., Eby P., 2008, Climate change and the effects of temperature extremes on Australian flying-foxes, Proc. R. Soc. B, 275, 419-425. 